\title{
The Matthew effect in health development
}

\author{
K S Joseph
}

\begin{abstract}
A study was conducted examining the paradox that populations with a poor standard of health seem to achieve only meagre improvements over time, whereas those with a good standard of health seem to show continual, substantial improvement.

The health states of 122 nations were measured by reference to their infant mortality in 1965 and the changes that occurred over the next 20 years. Countries with low infant mortality in 1965 (for example, Japan and East Germany) achieved substantial, further declines over the 20 years, whereas in countries such as Rwanda and Ethiopia infant mortality hardly declined at all or even increased (Ethiopia 165/1000 to 168/1000).

In 48 countries for which data were available there was a close link between the change in health state of a people and the ratio of government expenditure on health and defence. As the ratio increased in favour of defence, so the improvement in health state of a people declined; the reverse was also true.

At the primary care level disparity in uptake of care both among and within communities was associated with literacy and socioeconomic state, services inadvertently being aimed at those sections most likely to benefit.

The forces that act to produce this setting of unequal care must be checked at both national and primary levels if we are to have "Health for All by the Year 2000.”
\end{abstract}

\section{Introduction}

In 1968 Robert Merton described a psychosocial phenomenon in science which he labelled the Matthew effect ${ }^{1}$ :

Unto every one that hath shall be given, and he shall have abundance; but from him that hath not shall be taken away even that which he hath.

St Matthew xxiv, 40

Merton showed that the phenomenon was responsible for the allocation of excess credit to already famous scientists and the simultaneous diminished recognition accorded to unknown scientists for comparable work. This paper describes a similar phenomenon which occurs in health development. The paper examines how the magnitude of improvement in the health state of a population seems to be linked to the prior health of that population; those communities that have achieved a good standard of health tend to make further improvements at a rapid rate, whereas those with a poor standard of health may even show a deterioration with time.

Medical College, Vellore 632002, South India

$\mathrm{K}$ S Joseph, MD, research officer

BrMed f 1989;298: 1497-8 Global evidence

The change in the infant mortality statistics of nations between 1965 and 1985 offers a striking illustration of the Matthew effect. Countries like Japan and the Democratic Republic of Germany which had attained low infant mortality by 1965 achieved the maximum rates of change in infant mortality over the next 20 years. Conversely, those countries which had high infant mortality in 1965 could manage only minimal changes in the same period (table I). Rwanda, with an infant mortality of $141 / 1000$ in 1965 , was able to reduce the rate by a meagre $10 \%$ (to $127 / 1000$ ). On the other hand, Ethiopia recorded an increase in infant mortality from $165 / 1000$ to $168 / 1000$ in the same 20 year period. In clear agreement with the Matthew effect, countries with a good health state were able substantially to consolidate their gains, whereas those with a poor standard of health like Ethiopia suffered a worsening in their people's health.

TABLE I-Infant mortality statistics of selected countries in 1965 and 1985 and rates of change over period

\begin{tabular}{lrrr}
\hline & \multicolumn{3}{c}{ Infant mortality/1000 } \\
\cline { 2 - 3 } & 1965 & 1985 & \\
\hline Japan & 18 & 6 & $-66 \cdot 7$ \\
Democratic Republic of Germanye & 25 & 10 & $-60 \cdot 0$ \\
Greece & 34 & 16 & $-52 \cdot 9$ \\
Malaysia & 55 & 28 & $-49 \cdot 1$ \\
Sri Lanka & 63 & 36 & $-42 \cdot 9$ \\
Mexico & 82 & 50 & $-39 \cdot 0$ \\
Zimbabwe & 103 & 77 & $-25 \cdot 2$ \\
Kenya & 112 & 91 & $-18 \cdot 8$ \\
Rwanda & 141 & 127 & $-9 \cdot 9$ \\
Ethiopia & 165 & 168 & $+1 \cdot 8$ \\
& & & \\
\end{tabular}

^Data from World Bank development report, 1987.

TABLE II-Mean percentage changes in infant mortality 1965-85 and ratios of defence to health expenditure 1972-83*

\begin{tabular}{lcccc}
\hline $\begin{array}{l}\text { Infant } \\
\text { mortality/1000 } \\
(1965)\end{array}$ & $\begin{array}{c}\text { No of } \\
\text { countries }\end{array}$ & $\begin{array}{c}\text { Mean \% change in } \\
\text { infant mortality, } \\
1965-85\end{array}$ & $\begin{array}{c}\text { Mean \% change in } \\
\text { ratio of defence } \\
\text { expenditure to } \\
\text { countries }\end{array}$ & $\begin{array}{c}\text { nealth expenditure, } \\
1972-83\end{array}$ \\
\hline$<50$ & 35 & $-53 \cdot 9$ & 16 & $-13 \cdot 9$ \\
$50-99$ & 19 & $-51 \cdot 2$ & 10 & $+5 \cdot 7$ \\
$100-149$ & 35 & $-36 \cdot 4$ & 14 & $+34 \cdot 1$ \\
$\geqslant 150$ & 33 & -26.9 & 8 & $+50 \cdot 7$
\end{tabular}

*Data from World Bank development reports, 1986 and 1987.

Table II shows the mean rate of change in infant mortality during $1965-85$ for 122 countries classified according to their infant mortality figures in 1965 . The association between the rate of change in infant mortality and the baseline figure showed a striking inverse relation. Though it is widely accepted that it is easier to tackle the postneonatal component of infant mortality than the neonatal component, the global experience during the 20 years seemed to show the reverse.

Table III shows the ratios of defence to health expenditure for selected countries in 1972 and 1983. The percentage rates of change in the ratios between the two years showed a link with the prior health states 
TABLE III-Infant mortality in various countries in 1965 and ratios of defence to health expenditure in 1972 and 1983 and percentage changes in these ratios

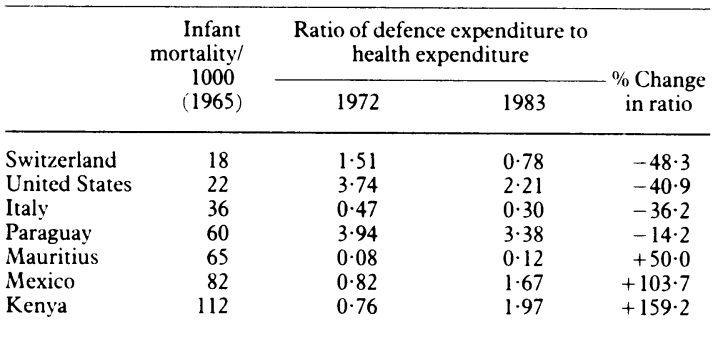

^Data from World Bank development report, 1986.

of the countries. Those countries which had low infant mortality recorded changes in their ratio of defence to health expenditure which favoured health, whereas those countries which had higher infant mortality recorded a change in the ratio which neglected health. Put differently, the populations of those countries whose health state was good (as assessed by low infant mortality) received greater inputs further to improve their health, whereas the populations of countries whose health state was poor suffered a decrease in expenditure on health (that is, relative to that on defence). Analysis of 48 countries for which data were available showed that the relation between health state and change in the ratio of defence to health expenditure was in perfect agreement with the principle of the Matthew effect (table II).

\section{Matthew effect in primary health care}

A good example of the Matthew effect operating in a primary health care setting was described in a study in south India. ${ }^{+}$An investigation into the reasons for disparate immunisation coverage among 68 rural villages showed that a high rate of immunisation was associated with the presence of a community health worker. Further analysis, however, disclosed that the association between the presence of a community health worker and the immunisation coverage was not causal. Rather, immunisation coverage was dependent on other factors-namely, the literacy and socioeconomic states of the communities. The confounding association occurred because the educated, richer villages were the ones that readily came forward to appoint community health workers when the scheme was offered. The less well educated, poorer villages did not respond positively to the community health worker scheme and therefore did not receive the benefits of this programme. Another study pointed out the occurrence of an identical phenomenon elsewhere, where it was found that despite community participation in the selection process the community health workers were biased towards serving the richer farmers rather than the poor labourers.

Another example of the Matthew effect occurs when agencies working with rural populations lay down criteria for extending their programmes to new areas. For instance, some primary health care programmes insist on a community contribution and community participation before undertaking to extend their comprehensive health service scheme to new villages. Inevitably the more health conscious and better educated and organised villages respond positively and gain the benefits of the programme. On the other hand, the villages which do not cooperate are almost invariably the less well educated, less organised, poorer ones, whose need for a primary health care programme is greater. Even when such programmes are extended to both types of communities the inherent differences lead to a differential in delivery of services. Facing greater frustration in getting health messages across and eliciting cooperation from the poorer communities, health personnel tend to become cynical as their initial enthusiasm wanes and the lack of dramatic results becomes obvious. Programmes which lay down criteria for extending their services are able to guarantee quick "success" by virtue of inadvertently selecting out the section of the community most likely to benefit in a short time.

The Matthew effect may be manifested in small ways even in the doctor's outpatient clinic. The well educated, richer sections of the community understand and can comply with the doctor's instructions more easily. The less well educated patients, unable to follow instructions, end up irritating the health personnel, which not infrequently causes them to be treated with less understanding. These encounters tend to alienate the poorer communities further.

These difficulties commonly occur in primary maternal and child health care programmes, where the doctors are often frustrated at the very outset by the uneducated mother's inability to recall the date of her last menstrual period. In this setting also domestic circumstances force the poor, high risk antenatal patient to forgo the benefits of a hospital delivery, so that hospitals find themselves catering for the socioeconomically better off, non-high risk group of patients.

\section{Combating the Matthew effect}

The declaration of Alma-Ata stated that the existing gross inequality in the health of the people, particularly between developed and developing countries, as well as within countries, was unacceptable. Emphasising that this inequality was of common concern to all countries, the declaration called for the attainment of "Health for All by the Year 2000." The roots of the phenomenon responsible for the prevailing situation, however, lie deep within the social fabric of communities. Plainly a philosophical gap exists between the idealistic vision of those who signed the health for all declaration and the method of functioning of health personnel in the existing health systems.

Correcting obvious discrimination in the form of biased allocation of resources will require a firm commitment by the governments concerned. The more subtle mechanisms responsible for producing the Matthew effect, however, must be tackled at the primary health care level by health managers. A clear conceptualisation of the objectives to be served, close supervision of workers, and use of managerial tools such as continuous evaluation will help to achieve this end.

1 Merton RK. The Matthew effect in science. Science 1968;159:56-63.

2 World Bank. World development report. Oxford: Oxford University Press, 1987. 3 World Bank. World development report. Oxford: Oxford University Press, 1986. Joseph A, Abraham S, Bhatacharjee S, et al. Improving immunization coverage. World Health Forum 1988;9:336-40.

5 Agarwal A. Barefoot doctors: symptom not cure. Nature 1979;280:716-8.

Accepted 17.Murch 1989) 